\title{
CFD DESIGN STUDIES FOR AMERICA'S CUP 2000
}

\author{
Bruce S. Rosen ${ }^{* \dagger}$ \\ South Bay Simulations, Inc., Babylon, NY 11702 \\ Joseph P. Laiosa ${ }^{\dagger}$ \\ Fluid Motion Analysis, Inc., Huntingtown, MD 20639 \\ Warren H. Davis, Jr. ${ }^{\dagger}$ \\ East Islip, NY 11730
}

\begin{abstract}
$\underline{\text { Abstract }}$
Computational Fluid Dynamics (CFD) plays an ever increasingly important role in the design and analysis of racing sailboats and in particular America's Cup yachts. The pervasiveness of CFD in the design process is demonstrated by a wide range of applications, concentrating on hull and underwater appendage design, from two of the US syndicate entries, Young America and AmericaOne, from just completed America's Cup 2000 races in Auckland, NZ. The CFD methods employed generally span a wide range, but the freesurface panel method SPLASH and the overset NavierStokes code Overflow are highlighted here. Discussion includes the CFD tools employed, how they are made to fit into the design process, and specific applications directed at hull and appendage design.
\end{abstract}

\section{Introduction}

Computational Fluid Dynamics (CFD) plays an ever increasingly important role in the design and analysis of racing sailboats and in particular America's Cup yachts. Computational methods, and CFD in particular, are critical tools in the hydrodynamics of hulls and appendages, the aerodynamics of sails, structural optimization of the hull, mast and rigging,

\footnotetext{
* President South Bay Simulations, Inc.

$\dagger$ Senior Member AIAA

Copyright $(92000$ by South Bay Simulations, Inc. Published by the American Institute of Aeronautics and Astronautics, Inc. with permission.
}

sailing performance simulations and statistical racing analysis. Both of the US syndicates of interest here Young America and AmericaOne had groups of specialists working all of these areas, employing the latest in computational methods. This paper concentrates on only one of those areas, some effects of CFD, in particular the SPLASH ${ }^{1-3}$ code, on the hydrodynamic design of the hull and underwater appendages.

The application of CFD tools have for years formed the basis of design methods in the aircraft industry. CFD for yachts started to gain importance in 1983, when John Bertrand on Australia II with its high tech winged / inverted keel took the cup from Dennis Connor on Liberty, breaking the longest winning streak in the history of sports (132 years). Technology, from any and every design aspect, was sought to bring the cup back to the US, and CFD benefited from that urgency. From our perspective, that movement began our involvement with the design program for Dennis Conner's 12-metre yacht Stars and Stripes '87. For that campaign, vortex lattice, panel codes and even some initial Navier-Stokes methods were all brought to bear on the underwater design. Dennis Conner recaptured the Cup in Perth, Australia, returning the cup to the U.S. and the San Diego Yacht Club in 1987. The importance of CFD in the design process has never looked back from that point, and has slowly seen its role increasing from Cup to Cup. 
We have been involved in every multichallenge Cup cycle since that time (races are usually held every 3-5 years only). For the 1992 races we worked with the Partnership for America's Cup Technology and, to a limited extent, with Team Dennis Conner. For the 1995 races we worked closely with the PACT-95 syndicate to help develop Young America, and with Fluid Thinking, Ltd., leading to the yacht Sydney 95 and the two sister yachts oneAustralia. For the 2000 America's Cup our design services were exclusively committed to the New York Yacht Club/Young America design team and the Young America yachts (Rosen and Laiosa), and to the AmericaOne design team and the AmericaOne yachts (Davis). The SPLASH free-surface software package was also licensed for use by the U.S. Virgin Islands syndicate (prior to its being absorbed by Team Dennis Conner) and by $\boldsymbol{C A D E}$, the Spanish America's Cup challenge.

With each subsequent America's Cup cycle, we have made increasing use of and design impact with the SPLASH software, and with other (viscous) CFD tools. We have also seen a number of CFD efforts by other teams, although little has been reported or published about the detailed development, use and application of other tools by other researchers. Nevertheless, the cost and accuracy benefits of CFD versus physical model tests are such that we expect the use of numerical methods to increase further during the next design cycle (with races to again be held in Auckland, NZ, in 2003).

Each of the authors has a distinguished career in the field of aerodynamic design and analysis for military aircraft, as employees of Grumman Corporation (now Northrop Grumman). Laiosa recently left to work in the Aircraft Division of the Naval Air Warfare Center in Patuxent River, MD. In this regard we have experience with a wide range of CFD tools. For America's Cup applications, however, our primary focus has been on development and application of the SPLASH free-surface panel code.

\section{Calculation Method}

For the 1987 Cup, SPLASH was simply a modification to the NASA version of the VSAERO code $^{4}$. For the 1992 design programs, SPLASH was completely rewritten for improved performance and results in particular with respect to free-surface flows.

As is the case with panel codes, panels are distributed over the model surfaces, including the wakes shed from the keel, winglet and rudder. Figure 1 shows a typical SPLASH panel model.

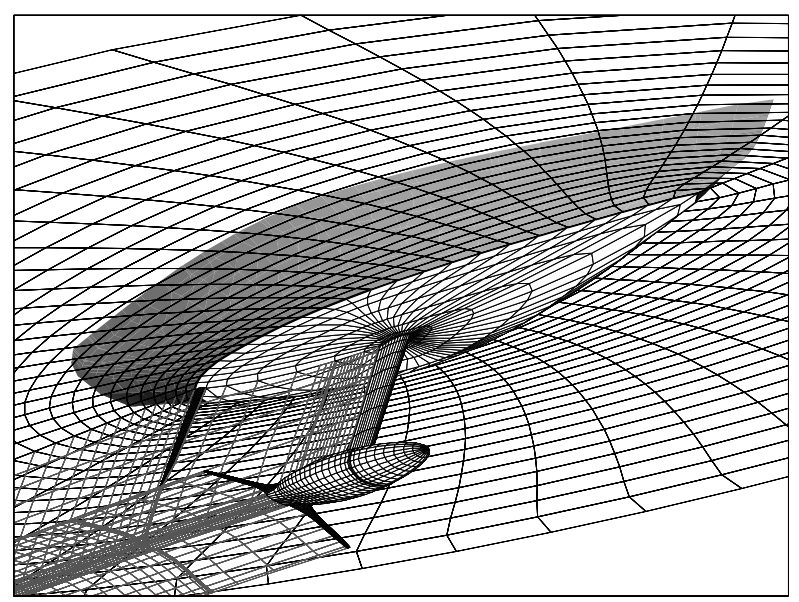

Figure 1: SPLASH panel model, fully appended

Over each panel is distributed a constant source and/or doublet singularity, which automatically satisfies the governing incompressible, inviscid potential flow equation

$$
\nabla^{2} \Phi=0
$$

where $\Phi$ is the potential and $\nabla \Phi=(\mathbf{i} \partial \Phi / \partial \mathrm{x}+\mathbf{j} \partial \Phi / \partial \mathrm{y}$ $+\mathbf{k} \partial \Phi / \partial \mathrm{z})$ is the corresponding velocity.

Like VSAERO, SPLASH uses an internal zero-perturbation boundary condition $\left(\varphi_{\mathrm{i}}=0\right)$. This is a particularly convenient choice when using both sources and doublets to satisfy the external boundary solidsurface boundary condition $\mathbf{V} \bullet \mathbf{n}=0$, and leads to an extremely robust method. With this approach, only the panel-to-panel potential influence coefficients are required, rather than the three $(\mathrm{x}, \mathrm{y}, \mathrm{z})$ sets of velocity influence coefficients. Furthermore, the panel source strength is then directly related to the panel normal velocity, and may therefore be set a priori based on the external boundary condition. The internal boundary conditions then yield an $\mathrm{N}$ by $\mathrm{N}$ matrix ( $\mathrm{N}$ being the number of panels) to be solved for the unknown panel doublet strengths. Finally, the panel tangential velocities are related to the local surface gradient of doublet strengths, which are determined using panel-topanel 3-point central finite difference formulae.

It is in the treatment of the free-surface that SPLASH differs from other (free-surface) panel codes. 
To start, the internal zero-perturbation boundary condition for solid surfaces is extended for use also on the "other side" of free-surface panels. Next, a higher-order finite-difference scheme is employed for the pressure gradient term in the freesurface boundary condition

$$
\left(\mathrm{U}_{\text {model }}\right)^{2} / 2 \mathrm{~g} \partial\left(\mathrm{c}_{\mathrm{p}}\right) / \partial \mathrm{s}+\partial \eta / \partial \mathrm{s}=0
$$

The finite-difference algorithm is similar to that first proposed by Dawson ${ }^{5}$, but features a stencil which "rotates" so that the upwind streamwise pressure gradient may be obtained independent of the orientation of the free-surface panels. Another distinguishing feature is the ability to difference across wakes, such as on the hull and free-surface downstream of the keel and rudder, across the roots of the keel and rudder wakes. This feature is not available in other codes such as VSAERO, which therefore require the use of one-sided finite difference stencils on surfaces adjacent to the trailing wakes. One-sided stencils are not only less accurate, but their use in the free-surface boundary condition have been found to incorrectly account for the proper domain of dependence with respect to propagation of free-surface waves. Finally, the freesurface boundary condition is cast in a smallperturbation form, allowing the models and flow solutions to be iterated upon to achieve nonlinear solutions for the free-surface elevation $\eta$ (as well as for the sink and trim).

We cannot overemphasize that these distinguishing features of SPLASH are at least partially responsible for its relative success as applied to freesurface problems. The resulting methodology provides a very reliable flow field simulation, which accounts simultaneously for wave drag and lift-induced drag effects. The otherwise inviscid results also provide a very solid basis for improved viscous drag estimates arising not only from wetted area variations but also due to airfoil section viscous drag-due-to-lift.

SPLASH capabilities include both steady nonlinear free-surface solutions and unsteady partially nonlinear solutions in the frequency domain. The handling of large numbers of runs for full tow tank simulations including iterated sink and trim are all scripted automatically, and as such, coordination between SPLASH results and performance prediction programs is facilitated.
SPLASH steady capabilities include...

- 3D interacting solution for nonlinear free-surface wave, hull and appendage flow fields

- Fully appended yacht (keel, bulb, wing, rudder) including heel, yaw, tab and rudder deflections

- Automated panel modeling from NURBS surfaces

- Automated free to sink and trim with sail forces

- Automated post processing for 6 DOF forces including viscous stripping

- Used in hydro force surface development for VPP simulations

SPLASH seakeeping capabilities include...

- 3D interacting solution for 'partially nonlinear' free-surface wave, hull and appendage flow fields

- Unsteady flow, and motions, oscillate harmonically for ship and incident wave

- Full 6 DOF capability for appended yacht including heel, yaw, tab and rudder deflections and arbitrary incident wave heading

- $1^{\text {st }}$ and $2^{\text {nd }}$ order forces and moments; motions and added resistance predictions

- Seakeeping resistance estimation for use in VPP simulations

\section{Physical versus Numerical Towing Tank Tests}

The ability of SPLASH to calculate six degree of freedom forces including wave, induced and simple viscous forces for all of the underwater yacht components (hull, keel, bulb, wing and rudder) at the full range of operating conditions (sink, trim, heel, yaw, tab/rudder deflection) allows it to play a variety of roles in the design process. One of SPLASH's most powerful roles is that of a numerical tow tank. Full tow tank tests can be run in SPLASH, using an automated scripting process. The final forces are then post processed just as the physical tow tank test results would be, to be then available for the sailing analysis program. The final result being an accurate ranking of boat sailing performance. SPLASH calculated forces have been used successfully in this type of process on an absolute basis and as deltas built off of a few selected physical tow tank tests. While the delta method attempts to track the physical tests more closely than the absolute approach, the uncertainties associated with the physical testing process and the increasing accuracy of the numerical tests may make the extra work to develop deltas unnecessary. A case can be made that numerical tank testing can deal more directly with these uncertainties yielding more consistent results than physical testing. 


\section{Physical Towing Tank Tests}

Traditional, physical model tests in a towing tank are very expensive. The towing tank budget for Young America was probably on the order of one million dollars and yet only about 16 complete model tests were conducted, the majority to investigate hull form. Perhaps $\$ 20,000$ and 3 weeks are required to construct a hull model. Tests were conducted with a standard set of appendages (keel/bulb/wing and rudder) due to the excessive costs that would have resulted from building correctly sized appendages for each different hull. A good set of model appendages might cost $\$ 40,000$ and require 8 weeks for fabrication. Finally, test costs can run close to $\$ 4,000$ per day for tank and test engineer fees, and can take two weeks to complete. Thus tow tank testing can easily take a significant portion of the limited budget of any design team.

Testing yacht models in towing tanks is in many ways more demanding than testing of aircraft in wind tunnels, particularly since the model is typically free to sink (up or down) and trim (bow up or bow down). Sink and trim have significant influence on yacht performance, so it is important that tank tests properly model the full-scale sink and trim at each test point. This is usually accomplished via sail force trim weights. These are added or moved around on the model to account for missing items such as crew weight, gear weight and, most importantly, the sail forces (which act so as to drive the bow down and, at heel, to also push down on the entire model). Distinct values of sail vertical force and trim moment are generally specified for each point in a model test matrix, which typically consists of up to 200 distinct test points (each corresponding to a particular value of heel, forward speed, yaw, and keel-tab/flap and rudder deflection).

Tank testing is further complicated by other matters that need to be taken into account including: different vertical center-of-gravity of the model versus the full scale yacht; model tow height; different viscous forces acting on the model (at small Reynolds number) versus the full scale yacht (at high Reynolds number); turbulence stimulation and its effect on measurements of lift (side-force) and drag; etc. Tank conditions (density and viscosity) must constantly be monitored. Model conditions (heel, speed, yaw, tab and rudder) are usually difficult to achieve precisely and are best recorded for each individual test point.
Other complications include the effect of the tank bottom and side walls on the hydrodynamic flow in the tank, the reflection of free-surface waves from the walls, and the need to allow the tank to settle in between test points to allow any model-generated waves to disperse. A particularly difficult problem is that as the model is repeatedly towed down the tank at side force generating conditions, a cross-sectional circulation may develop which decays very slowly and which can compromise subsequent test runs. This has led to the use of baffles, nets, screens and other in-tank apparatus, which attempt to squelch the circulation without otherwise compromising the tests. In the end, tank testing can be a difficult undertaking, and even the best programs can sometimes yield uncertain results.

All these factors are considered just for testing models in smooth, calm water. Unsteady tests go one step further, attempting to measure the additional resistance due to a model moving in ambient waves. Many tanks are outfitted with wave makers, which are often used to generate monochromatic waves (i.e., of a particular wave length). The wave length is varied from run to run to obtain added resistance as a function of incident wave length. The results are then multiplied by an expected sea-state (a spectrum of wave energy versus wave length) to estimate the added resistance for a particular race location. Most such tests are run upright (at zero heel, yaw, tab and rudder) and in head seas. Unsteady testing at heel and yaw can introduce large and asymmetric forces which are difficult to contend with, and testing in oblique seas is all but impossible in most tanks (which tend to be fairly long but not very wide). The difficulties surrounding even upright tests in head seas are such that the results are often of questionable value, and many teams choose to forgo unsteady tests altogether.

Some of the difficulties associated with tank testing are indicated in Figure 2. This compares VPP performance predictions for the same models as tested by Young America several times over a period of many months. After considerable effort to refine model fidelity and test procedures, repeatability of 10 seconds around the course was achievable for this model across a middle band of wind speed. Obviously, physical tank tests are subject to some uncertainty arising from the difficulties involved. These uncertainties complicate the use of physical tests in the boat ranking process. Furthermore, the use of physical test results for validation of numerical results (including SPLASH) should be undertaken only with a critical eye. 

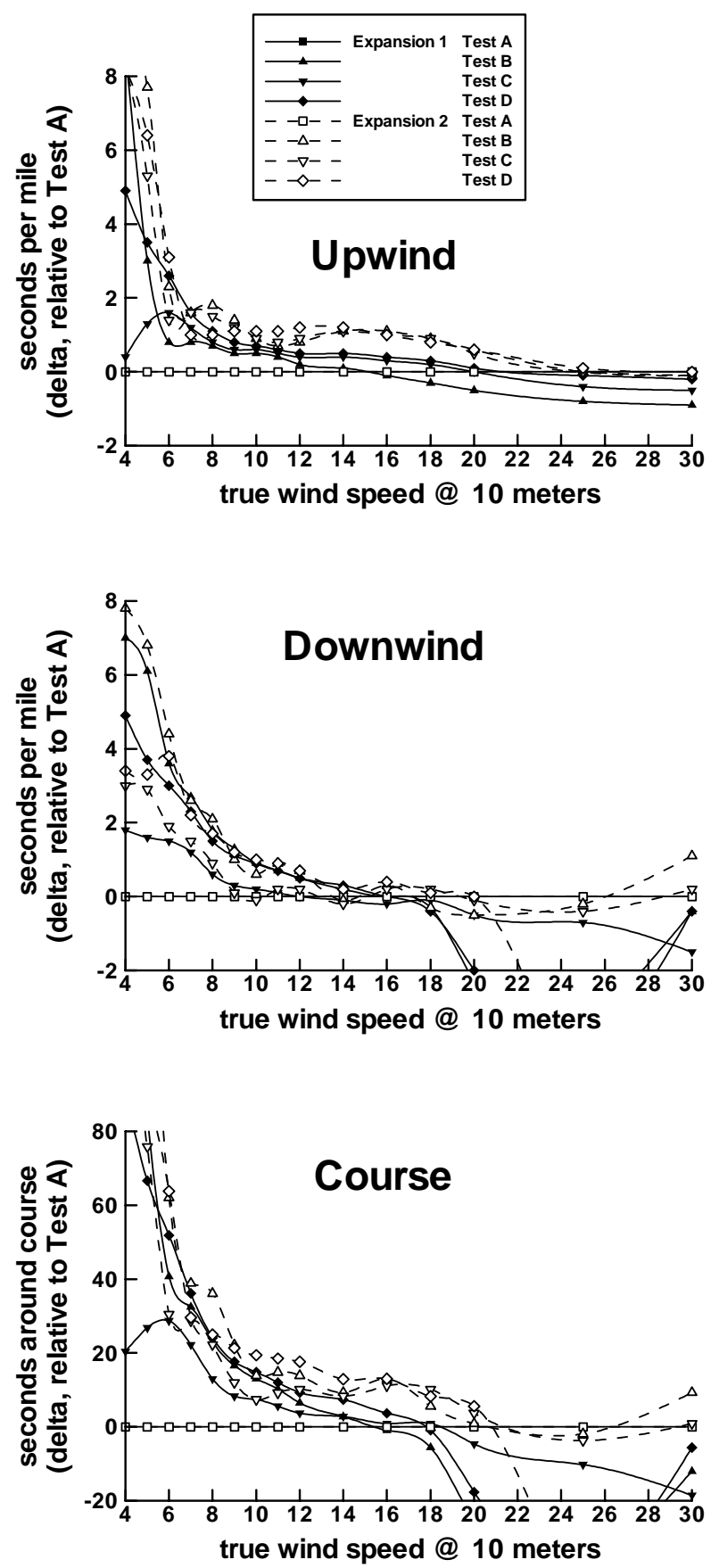

Figure 2: Comparison of VPP performance predictions for the same models as tested by Young America several times over a period of many months for upwind, downwind and full course cases.
Numerical Model Tests

With SPLASH for numerical tank testing, it is much easier to contend with many of these issues, or to avoid them altogether, and in some instances to calculate the undesirable physical tank effects. Numerical results are easily made for a half-infinite flow region (no bottom or side walls). For Young America, we made SPLASH calculations for tank models as tested in the tank with the standard set of appendages, and again with a set of appendages correctly sized for each particular full scale design. This provided estimates of "appendage corrections" to be applied to the tank results to account for associated differences such as in side force and drag (both wave and lift-induced) at model and full scale conditions. Computed hull wetted areas and wetted lengths were used to predict full-scale viscous drag, and also to analyze and correct the model-scale results obtained in the tank. Detailed spanload (section lift coefficient) information from the 3-D SPLASH numerical calculations were also used to incorporate 2-D viscous drag-due-to-lift predictions for the appendage foils. This was found to greatly improve our understanding of foil performance and its relationship to yaw balance and load sharing between keel and rudder. Collecting this type of spanload and wetted area information during physical tank tests (via photos, pressure taps, etc.) is prohibitively expensive and the results still may be of questionable accuracy.

Numerical testing may also be accomplished in much shorter periods of time. With SPLASH in the design loop we established standard file formats for the transfer of information between designers, CFD specialists, and VPP performance evaulators (who consider all the aspects of the yacht and the race conditions as well as the underwater hydrodynamics). SPLASH allowed full model tests ( 200 test points) to be carried out on a medium- to high-end desktop UNIX workstation in 8-12 hours of CPU time. A total turnaround time of 24-48 hours, from designer's drawing board to final full-scale race performance, was usually achieved. The same is not true of all numerical tools. The reliability of other free-surface panel codes for conducting complete model tests as described above has not been reported elsewhere.

More sophisticated tools such as free-surface viscous flow codes are apparently also not ready for routine model testing. In a recent paper describing one such state-of-the-art method ${ }^{6}$, for isolated hull forms which are free to sink and trim, viscous solver run times 
were reported to range from 30 to 50 hours of CRAY C-90 CPU time for just a single low-speed test point. The current authors believe that appended hull forms will require several times the computing resources as for isolated hulls, to properly model the keel, bulb, wing and rudder. Since evaluation of yacht performance requires a fairly complete test matrix, and more than just a few isolated test points, the use of viscous flow tools for general yacht design is probably not a viable near-term reality.

\section{The Velocity Prediction Program}

It is deceiving to simply look at hull/appendage upright drag rise or heeled drag polars from either numerical or physical tank testing to rank hull/yacht performance. A more multidisciplinary approach is required to account for the full integrated yacht performance. This is where the VPP (Velocity Prediction Program) comes into play. The VPP is the final analytical arbiter of sailing performance. It takes into account the interplay of the underwater hydrodynamic characteristics, the aerodynamics of the sails, the balance of the boat to sail specific course directions with respect to a variety of wind conditions, the structural aspects of the hull and appendages, the winds and waves expected on the race course location during the various racing periods leading up to and during the final Cup races and other effects, all critical factors in determining yacht performance. The final results of the VPP analyses are estimates of yacht speeds and sailing times around a course, the best true indicator of performance.

The Young America team pursued an approach whereby the raw SPLASH hydrodynamic predictions were fed directly to the VPP. The AmericaOne team adopted a different approach, using SPLASH results to predict boat-to-boat increments, which were then applied to physical towing tank results for a baseline model. Both approaches are viable if pursued vigorously, and each has its advantages and disadvantages regarding ease of implementation and reliability of results.

The Young America team also wanted a method which could be used to better distinguish the trade-offs relating to yaw balance and relative load sharing between keel, keel-tab, and rudder. We therefore implemented an approach using spanload information from SPLASH combined with viscous drag polars from 2-D airfoil analysis methods (primarily the $\mathrm{XFOIL}^{7}$ code) to better predict the full-scale yacht performance. This also allowed for an accounting of varying degrees of laminar versus turbulent flow on the foils. For a model test consisting of 200 test points, we used each of the 200 distinctly computed keel, rudder and winglet spanload distributions. This process was highly automated, with 3-D spanload and 2-D viscous drag polar files used to augment the inviscid SPLASH hydrodynamic data just prior to or during its use in the VPP.

Due to the complexities of evaluating performance, different approaches can lead to somewhat different results. This not only compromises the boat ranking process but also makes their use for validation of any numerical method, including SPLASH, difficult. Figure 2 also shows the boat-toboat comparisons based on Young America tank data also using two independent methods to interpret the data and to expand it to full scale. This was well along in the design program and some calibration between the two methods had by this time occurred (some but not all discrepancies were due to differences in how the two methods interpolated between discreet data points). Still, there is not complete cross-correlation between the relative boat-to-boat performance predictions from the two methods. In most cases it is not a question of one approach being better than the other, both may be reasonably valid. For such reasons, many teams regularly make use of more than one data analysis method or VPP program to provide as much insight as possible into model-to-model performance comparisons.

\section{Specific Applications and Benefits of CFD}

For the Young America design team, we carried out a total of approximately 200 steady and 27 unsteady numerical tank tests with SPLASH. This is compared to about 16 steady and no unsteady physical towing tank model tests. It must be emphasized that flow fields in the presence of a free-surface are highly nonlinear, so that the cumulative effects of several model changes are usually not additive. Thus there is a very high value associated with the ability to run a large number of complete model tests.

The 200 SPLASH steady numerical tank tests were used to support a wide variety of design goals, more typically investigated only in the tank, as follows ...

- hull form (shaping)

- hull parametrics (sizing)

- appendage (yaw/tab/rudder) effectiveness

- installed wing parametrics (sizing)

- keel planform design

- optimum bulb fineness ratio 
The 27 SPLASH unsteady tank tests supported similar type design goals...

- hull form

- hull sizing

- wing sizing

The SPLASH numerical tank tests devoted to hull form investigations included testing with both the standard "tank" appendages and with appendages correctly sized for each hull design. Typical hull parameters were investigated, such as: displacement; length; beam; prismatic coefficient (one measure of the longitudinal distribution of hull volume); location of center-of-gravity; location of center-of-flotation (centroid of the waterplane); bow, stern and mid crosssection shapes; topside flare; bow and stern overhang, and trim (e.g., crew placement). Of particular importance was the need for an early decision as to the bow shape, such as the trade-offs between a spoon or meter bow with a long overhang, and a plum or destroyer bow with a short or no overhang. Both tank and numerical tests were run, and results also benchmarked against designs from previous programs such as the 1995 yachts Young America and Tag Heuer. The use of SPLASH allowed a considerably more thorough investigation of parameters compared to the experimental tank program.

A large number of SPLASH tank tests involved parametric variation of model displacement, length, and beam, each of which have a direct firstorder effect on the full-scale yacht performance. These "sizing" tests were conducted after the team had first investigated and decided upon what general type of hull form would be pursued. The parametric variation of the hull sizing parameters is shown in Figure 3a, along with typical VPP results for a 2-D plane cut through the 3-D parametric design space, Figure $3 \mathrm{~b}$.
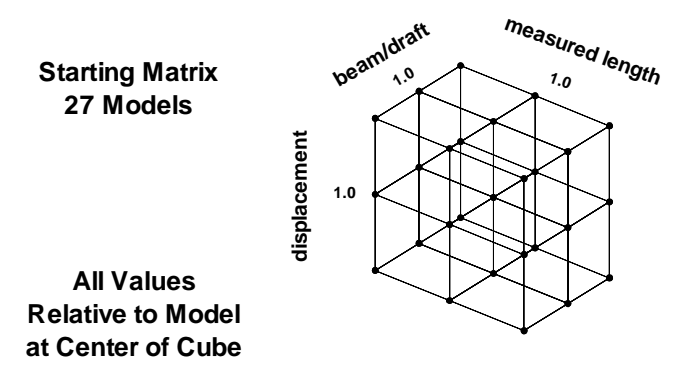

Figure 3a: Cube of hull sizing parametric variations
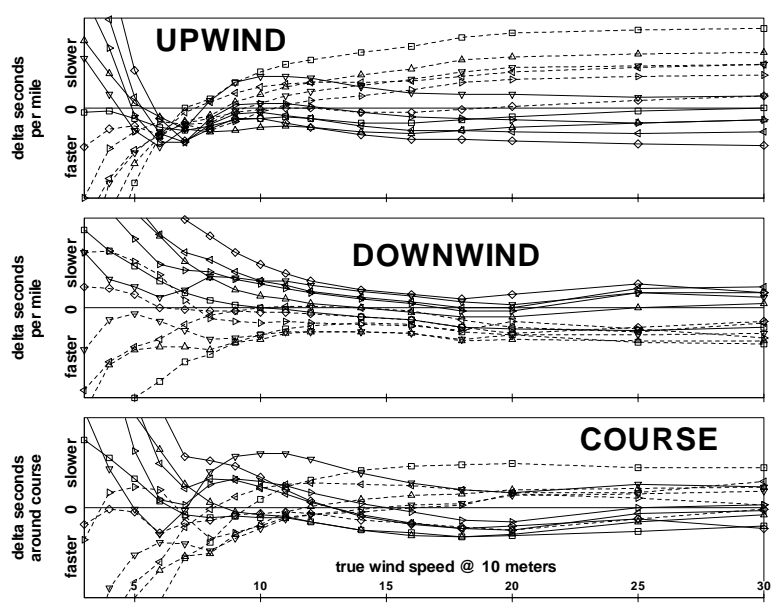

Figure 3b: SPLASH-based VPP results for a 2-D plane cut through the 3-D hull design space.

Corresponding SPLASH-based VPP results for optimum length, beam and displacement compare very favorably with the existing body of knowledge based on numerical and experimental (both model and full scale) results from Young America and other previous IACC design programs.

Detailed design information on appendage performance requires a highly expanded test matrix of yaw, tab and rudder angles, to investigate and optimize the efficiency of each for generating side force in the presence of the free-surface. Several SPLASH tank tests were devoted to these appendage studies. Due to the perceived importance of these issues, and the highly sensitive nature of the trade-offs involved, physical towing tank tests were similarly conducted. The results from the physical tank tests and the numerical calculations are compared in Figure 4.

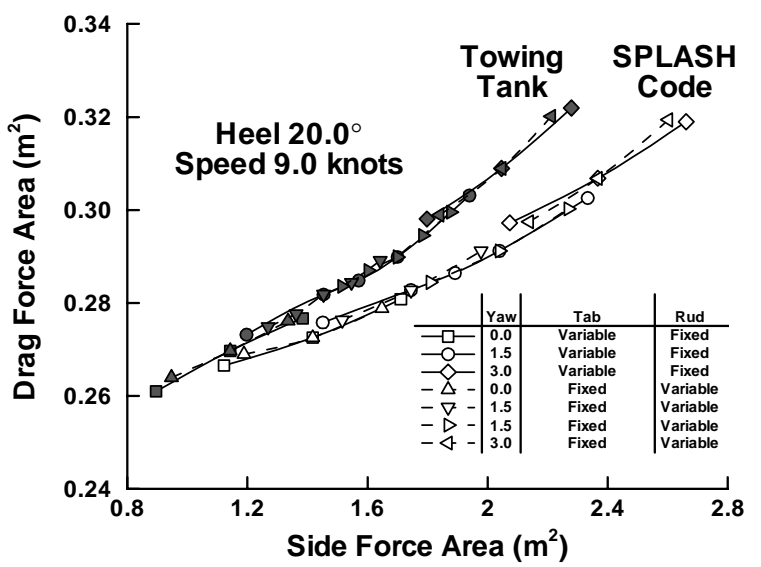

Figure 4: SPLASH appendage effectiveness correlates well with tow tank data 
Changes to the SPLASH program's transpiration boundary condition (to simulate device deflections) during the Young America effort improved predictions for all-moving surfaces such as the rudder, leading to a much better correlation with physical test data.

Such data and the VPP allow a determination of optimum yaw, tab and rudder settings for minimum drag at upwind sailing conditions. It was found that adding the 2-D viscous airfoil drag polar results (based on 3-D SPLASH spanloads) to inviscid SPLASH results improved the correlation between optimum values derived from the tank and from SPLASH. Obvious in both the tank data and the SPLASH results was that rudder effectiveness varies considerably with both heel and forward speed. Yaw balance and load sharing issues therefore cannot be properly addressed by methods that do not include the nonlinear effects due to the free-surface waves at heel and yaw. The team used this approach to study the effect of constraining the yaw moment to a certain value (as required to balance the moment due to the sails) relative to the optimum unconstrained yaw, tab and rudder angles.

An extensive matrix of SPLASH numerical tank tests were run to investigate parametrically the trade-offs relating to winglet size (span, area, and taper ratio). The results indicated that a good degree of taper was desirable, but once taper (and chord) was

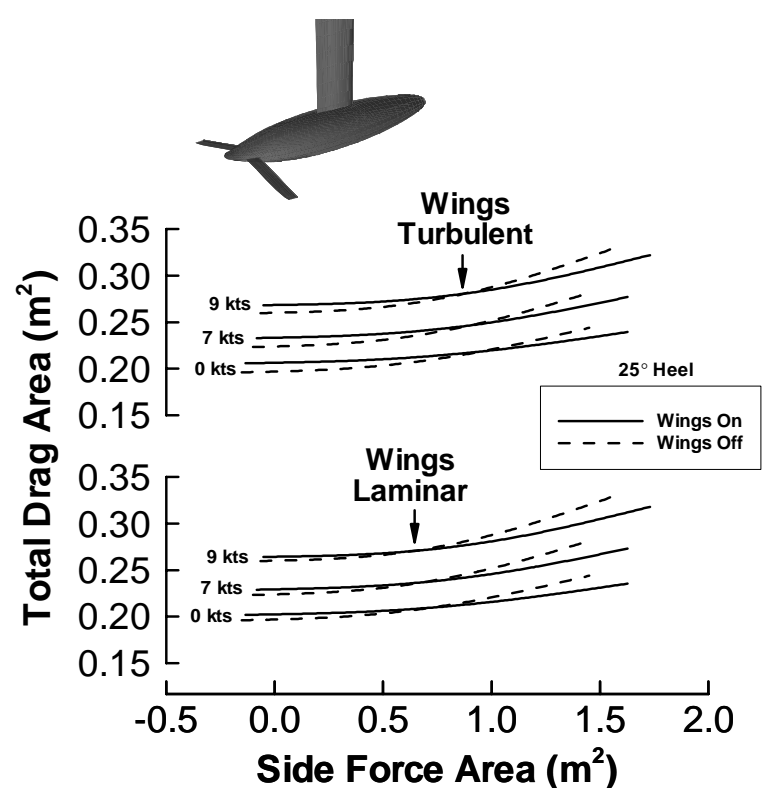

Figure 5: Winglet benefits are realized as side force and speed are increased, with crossover dependent on turbulent transition. fixed, the upwind performance was surprisingly flat over a fairly wide range of winglet span. Physical tank tests may not be sensitive enough to establish such trending. A few final tests were run to assist selection of final leading edge and trailing edge planforms, including nonlinear planform shapes.

The preceding winglet sizing results contained certain assumptions regarding laminar versus transitional flow. Such considerations can alter the conclusions. In Figure 5, drag polars assuming laminar flow on the wings and assuming turbulent flow on the wings are shown. The point at which the winglet induced-drag benefits begin to outweigh their wetted area penalty is seen to depend on the state of the boundary layer.

SPLASH numerical tank tests were also used to investigate the effects of keel planform and taper, and the percentage of keel chord to be allocated to the trim tab. Figure 6 presents some results. Optimum spanwise loading in the presence of the free-surface was very different from expectations based on 12-meter and IACC studies from previous programs.

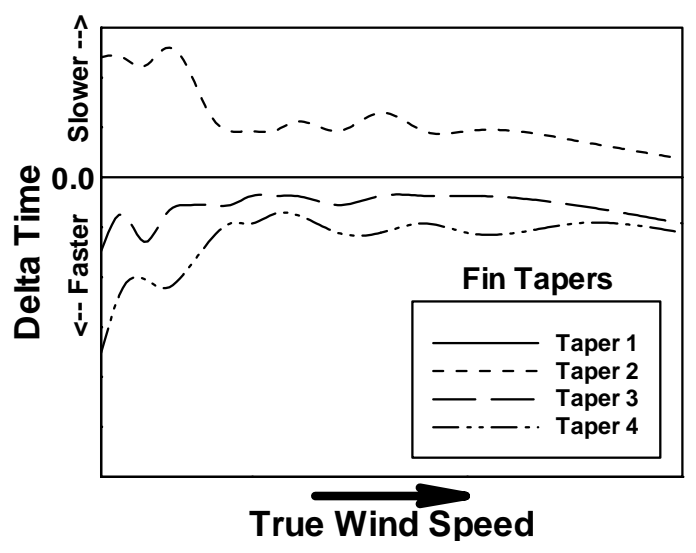

Figure 6: VPP time around the course for yachts with various keel tapers using SPLASH predictions.

A small number of tests were also run to determine the optimum bulb length-to-diameter ratio. SPLASH inviscid results were augmented with state-of-the-art transitional flow boundary layer predictions using the MSES code ${ }^{8}$. Typical VPP optimum results are shown in Figure 7. 


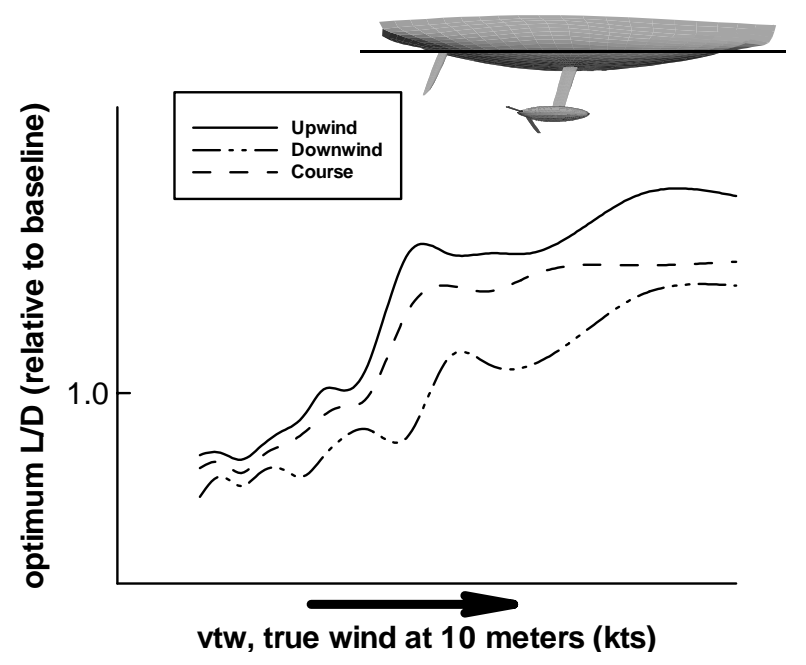

Figure 7: Optimum bulb L/D in the presence of the nonlinear free surface.

The influence of the nonlinear free surface results in a higher optimum bulb L/D compared to that for a bulb not interacting with free surface waves ${ }^{9}$. While detailed bulb design pressure distributions were determined by other team members using other tools, SPLASH results were used in the final stages to determine and to minimize any adverse hull and free-surface effects on the basic bulb design.

The use of unsteady SPLASH tank tests for seakeeping estimates of added resistance in waves followed a similar approach with a smaller number of numerical model tests, both upright and at heel and yaw, and in both head seas and oblique seas. These tests investigated hull and bow shape, hull sizing, and wing size (span), and expanded our knowledge of unsteady effects compared to our unsteady tank tests (none). SPLASH-based VPP's gave additional guidance to the team in its decisions regarding final choice of hull type and sizing, in light of the conditions expected in Auckland during the races. The unsteady wing sizing results were also very surprising. Looking at the predicted effects of winglets on added resistance in waves, as a function of incident wave length, it was difficult to see much of an effect. Furthermore, using a New Zealand sea spectrum, the optimum wing size was only a few percent larger than the optimum wing size in calm water. This was contrary to general experience on the water, that winglets noticeably improved performance in waves. But the New Zealand sea spectrum did not contain a lot of wave energy. When a San Diego sea spectrum, with much more wave energy, was used, the previously barely noticeable winglet effect translated into a rough-water optimum wing size some $30 \%$ larger than the calm-water optimum. This was more reasonable, and with these SPLASH results the team more confidently pursued smaller winglet designs for New Zealand conditions.

Perhaps one of the more interesting uses of the numerical predictions results from diagnosing the means used by Young America and by AmericaOne in the towing tank for turbulence stimulation of the model foils. Both teams used $1 / 3$ scale models, the maximum size permitted under the rules of the America's Cup. For turbulence stimulation, Young America used the traditional towing tank approach of studs approximately 0.1 to 0.125 inches in height and in diameter, placed every inch or so in the spanwise direction, and at one or two chordwise locations. As illustrated in Figure 8, Young America model tests consistently yielded lift (side-force) levels lower than expected compared to the SPLASH predictions.

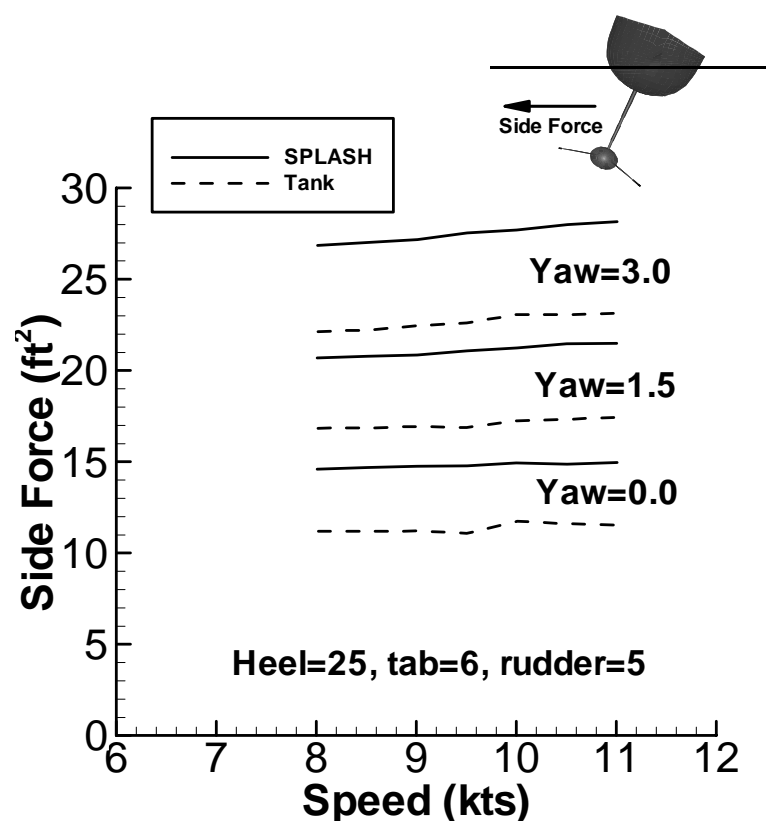

Figure 8: SPLASH vs. Tank Side Force for Young America configuration.

AmericaOne used a more modern, less invasive type of transition stimulator. Side force data from AmericaOne tests, as illustrated in Figure 9, showed better correlation with SPLASH predictions. The AmericaOne tests were able to achieve much closer agreement between experiment and calculation, with SPLASH generally within 5 to $10 \%$ above the tank test value, as might be expected from any inviscid flow code. 


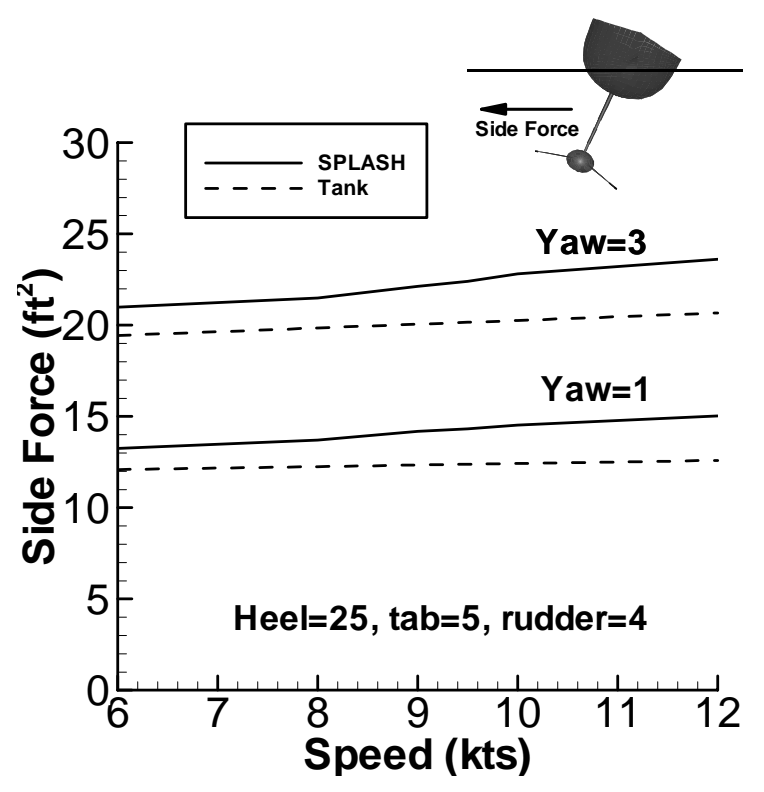

Figure 9: SPLASH vs. Tank Side Force for AmericaOne configuration.

The large discrepancy in the Young America side-force results was a major cause of concern during the design program. Further investigations revealed that the SPLASH constant source/constant doublet formulation and associated wake approximations, if anything, tended to slightly underpredict rather than overpredict the analytic potential flow lift. A viscous calculation by Laiosa using the OVERLOW $\operatorname{code}^{10}$ for a full 3-D model (including the SPLASH-computed nonlinear free-surface shape) was undertaken, Figure 10 , to further study the side forces.

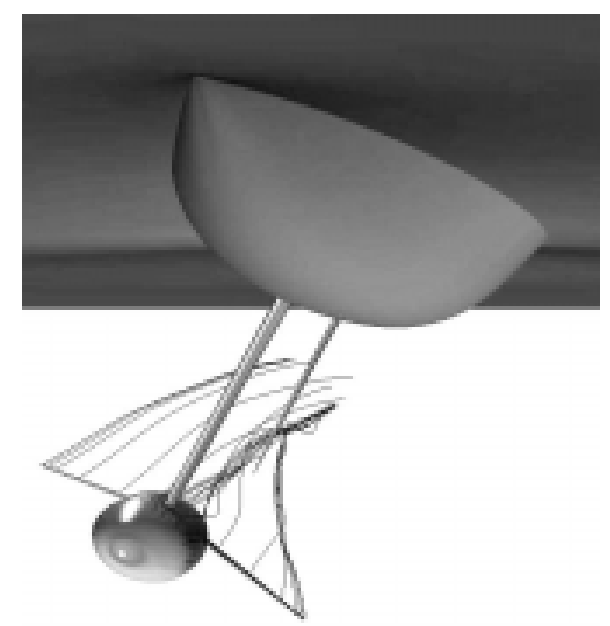

Figure 10: OVERFLOW Navier-Stokes calculation for full underwater configuration.
This calculation also showed extremely good correlation for side force as predicted by SPLASH and by OVERFLOW. Those side force results (for speed $=10 \mathrm{kts}$, heel $=30^{\circ}, \mathrm{yaw}=4^{\circ}, \operatorname{tab}=6^{\circ}$, rudder $=5.5^{\circ}$ ) are tabulated below.

- SPLASH side force $=30.35 \mathrm{ft}^{2}$

- OVERFLOW side force $=29.17 \mathrm{ft}^{2}$

- Tank test side force $=24.76 \mathrm{ft}^{2}$

The SPLASH results are just 5\% higher than the OVERFLOW (Navier-Stokes) calculation and, as before, $20 \%$ higher than the tank test. These SPLASH and OVERFLOW calculations were also compared in other ways, for example to confirm the effect of the stern wave on the rudder airfoil pressure distribution, as show in Figure 11.

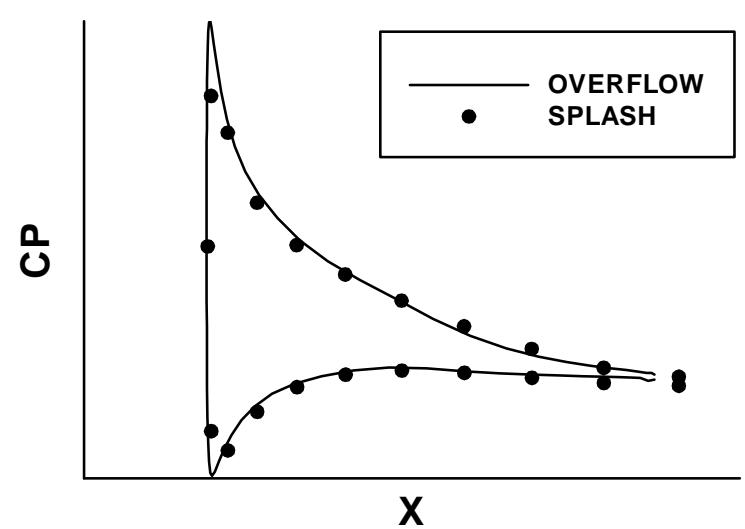

Figure 11: SPLASH vs. OVERFLOW rudder surface pressure comparison.

After considering the evidence, we believe some aspect of the Young America towing tank tests acted so as to reduce or spoil the generation of lift on the foil surfaces. Viscous effects, including the methods used for turbulence stimulation, are commonly suspect in such circumstances.

\section{Final Observations and Conclusions}

From the 1983 turning point in the America's Cup history to today, the use of CFD in the yacht design process has steadily and quickly increased. From the first tentative use of vortex lattice methods in the early years, to a strong reliance today on full numerical tow tank testing and limited, but powerful use of NavierStokes methods, CFD has established itself in a critical design role. While no CFD method should claim to replace all physical tank testing, neither would the exclusion of CFD be a wise use of limited resources. 
All these tools work best together in complementary roles to produce the highest performance configuration in shortest time and at lowest cost. The integration of SPLASH in particular into the design process has made possible the reliable screening and ranking of very large numbers of fully appended configurations in remarkably short periods of time, hours instead of weeks compared to physical tow tank testing, and at a substantial cost savings. In both the Young America and AmericaOne design efforts, SPLASH has been an integral tool, establishing a bit of a role reversal of CFD over expensive physical testing. SPLASH simulations played a lead role in hull design, with predictions accurate enough to be relied upon for realistic performance differences between designs, while physical testing was used periodically and to back up those results. A large role for CFD is again expected in the design efforts now starting or already underway for the next America's Cup in New Zealand in 2003.

\section{$\underline{\text { Acknowledgements }}$}

Young America results presented in this paper represent the combined efforts of the entire Young America design team. In particular, credit and attribution are given to: John Marshall (President), Duncan MacLane (Design/Technology Coordinator), Bruce Farr, Russell Bowler (Principal Designers, Farr Yacht Design, Ltd.), Jim Schmicker, Steve Morris, Britt Ward (Designers, Farr Yacht Design), Roberto Biscontini (Young America VPP), Dr. Jerry Milgram (Aerodynamic Design Consultant, MIT), Alexis Mantzaris (Data Expansion and VPP, MIT), Jim Teeters (Experimental Analysis, Sparkman \& Stevens / Langan Design Associates, Inc.), Olin Stephens (Aerodynamics), Rob Pallard (Tank Test, IMD), Paul Bogataj (Appendage Design), Dr. Mark Drela (Aerodynamic Consultant, MIT), Dr. Robert Ranzenbach (Appendage Consultant, University of Maryland), Erik Egleston (Design and Data), David Taylor Model Basin (Scale Model Tank Testing). The research reported in this paper was supported in part by funding from the Partnership for America's Cup Technology Foundation.

Acknowledgement of work performed for AmericaOne requires thanks to Paul Cayard, syndicate CEO, chief fund raiser and sailing skipper. The coordination of all design work, covering 35 experts in all technical fields, was led by Bruce Nelson (Nelson/Marek Yacht Design) Principal Designer and John Kuhn (SAIC) Technical Coordinator. Physical towing tank tests were conducted by Frank DeBord and Claudio Fassardi (SMS Technical Services).
Special thanks for support from Pointwise, Inc. (Gridgen, grid generation software) and Amtec Engineering, Inc. (Tecplot, graphing and visualization software) for supporting both the Young America and AmericaOne efforts.

\section{$\underline{\text { References }}$}

1. Rosen, B.S., Laiosa, J.P., "SPLASH Nonlinear and Unsteady Free-Surface Analysis Code for Grand Prix Yacht Racing," The Thirteenth Chesapeake Sailing Yacht Symposium, Annapolis, MD, Jan. 1997.

2. Rosen, B.S., Laiosa, J.P., Davis, W.H., Stavetski, D., "SPLASH Free-Surface Flow Code Methodology for Hydrodynamic Design and Analysis of IACC Yachts," The Eleventh Chesapeake Sailing Yacht Symposium, Annapolis, MD, Jan. 1993.

3. Boppe, C. W., Rosen, B.S., Laiosa, J.P., Chance, B., Jr., "Stars and Stripes '87: Computational Flow Simulations for Hydrodynamic Design," The Eighth Chesapeake Sailing Yacht Symposium, Annapolis, MD, Mar. 1987.

4. Maskew, B., "Program VSAERO: A Computer Program for Calculating the Non-Linear Aerodynamic Characteristics of Arbitrary Configurations," NASA-CR-166476, Dec. 1982.

5. Dawson, C.W., "A Practical Computer Method for Solving Ship-Wave Problems," $2^{\text {nd }}$ International Conference on Numerical Ship Hydrodynamics, Berkley, CA, Sep, 1977.

6. Subramani, A.K., Paterson, E.G., Stern, F., "CFD Calculation of Sinkage and Trim," Journal of Ship Research, Vol. 44, No.1, Mar. 2000, pp. 59-82.

7. Drela, M., "XFOIL: An Analysis and Design System for Low Reynolds Number Aerodynamics," Proceedings Conference on Low Reynolds Number Aerodynamics, University of Notre Dame, June, 1989.

8. Drela, M., "Newton Solution of Coupled Viscous/Inviscid Multielement Airfoil Flows," AIAA Paper 90-1470, June 1990.

9. Hoerner, S.F., Fluid Dynamic Drag, Midland Park, NJ, Hoerner, 1965.

10. Jesperson, D., Pulliam, T., Buning, P., "Recent Enhancements to OVERFLOW," AIAA Paper 970644, Jan. 1997. 